\title{
One-sided 4-out-of-5 Run Rules Charts for the Multivariate Coefficient of Variation in the Finite Horizon Process
}

\author{
Khai Wah Khaw ${ }^{1 *}$, XinYing CheW ${ }^{2}$, Ming Ha LeE ${ }^{3}$, Wai Chung YeOnG ${ }^{4}$, Sajal Saha5 \\ ${ }^{1}$ School of Management, Universiti Sains Malaysia, 11800 USM, Pulau Pinang, MALAYSIA \\ ${ }^{2}$ School of Computer Sciences, Universiti Sains Malaysia, 11800 USM, Pulau Pinang, MALAYSIA \\ ${ }^{3}$ Faculty of Engineering, Computing and Science, Swinburne University of Technology Sarawak Campus, 93350 \\ Kuching, .Sarawak, MALAYSIA \\ ${ }^{4}$ School of Mathematical Sciences, Sunway University, 47500 Petaling Jaya, MALAYSIA \\ ${ }^{5}$ Department of Mathematics, International University of Business Agriculture and Technology, Uttara, Dhaka, \\ BANGLADESH
}

\begin{abstract}
Quality improvement has been receiving great attention in industries. In recent years, the finite horizon process is commonly encountered in industries due to flexible manufacturing production. Past research works on finite horizon process monitoring are still limited. Because of this, one-sided 4-out-of-5 run rules charts are proposed to monitor the multivariate coefficient of variation in a finite horizon process. The performance measures of the proposed charts are derived using the Markov-chain approach. The proposed schemes can serve as a framework for practitioners who wish to perform process monitoring easily and efficiently. Numerical comparisons between the proposed and existing charts have been made, in terms of the truncated average run length and the expected truncated average run length criteria. The findings reveal that the proposed charts outperform the existing charts for detecting small and moderate process shifts in the finite horizon process.
\end{abstract}

Keywords: Statistics, finite horizon process, Markov-chain, run rules, statistical quality control

Received: March 3, 2021. Revised: July 29, 2021. Accepted: August 20, 2021. Published: September 15, 2021.

\section{Introduction}

Control charting techniques are commonly used in process signal detection to improve the quality of manufacturing and service processes. In the past few years, increasing attention has been paid to the application of control charting techniques to various industries, such as healthcare, chemical, biological, agriculture, service, etc. However, the mean and standard deviation of some processes are highly correlated, this may cause the control charts to lead to erroneous conclusions. To circumvent this drawback, the coefficient of variation $(\mathrm{CV})$ control chart is preferred to be used. The $\mathrm{CV}$ is very common and it is widely applied in various disciplines. For example, Babu and Sudha [1] applied the CV for reducing the speckle noise in ultrasound images. According to Karthik and Manjunath [2], the CV can be used to correct the unduly nonuniform distance between grid lines in noisy microarray images. Amelio [3] and Bakowshi et al. [4] presented the use of $\mathrm{CV}$ on sensory evaluation of virgin olive oil and injection pressure in a compression ignition engine, respectively. Additionally, the CV can be implemented to evaluate the global solar radiation in terms of time scale separation [5].

The first CV control chart was suggested by Kang et al [6]. Over the years, research works on $\mathrm{CV}$ chart have been extensively conducted to improve the sensitivity of the standard CV chart, in terms of the detection of small and moderate CV shifts, such as those by [7 - 10], etc. Besides, Yeong et al. [11] introduced a multivariate CV (MCV) chart to fill the research gap for multivariate process monitoring. Khaw et al. $[12,13]$ recommended the adaptive MCV and synthetic MCV charts to enhance the statistical performance of the standard MCV chart of Yeong et al. [11]. Chew and Khaw [14] presented the MCV chart by incorporating the variable sample size and sampling interval. Chew et al. [15] discussed the MCV chart with variable parameter. More recently, an exponentially weighted moving average
(EWMA) chart for monitoring the MCV was presented by Giner-Bosch et al. [16] while Haq and Khoo [17] suggested the adaptive EWMA MCV chart.

Note that the charts discussed in the preceding paragraph are used to monitor an infinite horizon process. In real-life scenarios, some of the production horizon processes are very short. The duration of a finite horizon process could be a few days or even less than a day. As industries are now moving towards specialization and diversification of products, as well as flexible manufacturing, the adoption of finite horizon processes has been increased [18]. Ladany [19] was a pioneer to present an economic optimization of a $p$-chart for a finite horizon process. Subsequently, research works to enhance the monitoring of a finite horizon process have received a lot attention, see $[20-21]$. In the context of MCV chart in a finite horizon process, Khatun et al. [22] and Chew et al. [23] implemented two one-sided Shewhart and run rules charts for monitoring the $\mathrm{MCV}$, respectively.

Meanwhile, the run rules scheme is continuously being investigated by many researchers. Tran et al. [24] used a run rules type control chart to monitor the ratio of two normal variables. Rakitzis [25] proposed the two-sided run rules control charts for monitoring exponential data. The proposed charts provided unbiased performances, as well as identify changes in the mean of a process from an exponential distribution. The runs rules median and $t$ control charts were recommended by Tran $[26,27]$ for monitoring changes in the process mean. Shongwe et al. [28] proposed the Shewhart $w$ of- $w$ standard and improved runs rules for both one-sided and two-sided charts based on the unified run length derivations.

Some quality practitioners prefer an intermediate chart for process monitoring due to its simplicity. In the context of 
the finite horizon, it is suitable to implement an intermediate chart, instead of an advanced chart, with consideration of the cost and time efficiency. In the existing literature, only the Shewhart (SH) and run rules (RR) MCV charts are available. However, Chew et al. [23] only investigated the efficiency of 2-of-3 and 3-of-4 run rules schemes. It is well documented that the 4-of-5 runs rules scheme is more efficient than the 2of-3 and 3-of-4 run rules schemes in certain cases [29]. The $\mathrm{SH} \mathrm{MCV}$ chart can detect large process shifts quickly but it is rather slow in the detection of small and moderate process shifts. The statistical sensitivity of the SH MCV chart can be enhanced by using supplementary run rules. This paper proposes two one-sided 4-out-of-5 run rules MCV (called as $\mathrm{RR}_{4,5} \mathrm{MCV}$ ) charts. The performance measures of the proposed charts are derived using the Markov-chain approach. As it will be shown in Section 3, the $R_{4,5} \mathrm{MCV}$ chart generally prevails over the existing 2-of-3 RR MCV, 3-of-4 RR MCV, and SH MCV charts in the detection of small and moderate shifts, in terms of truncated average run length (TARL) criterion.

The remainder sections are organized as follows: Section 2 discusses the design of the two one-sided $\mathrm{RR}_{4,5} \mathrm{MCV}$ charts.

The derivations of the formulae and algorithms to compute the TARL values, by adopting the finite horizon Markov-chain method are also illustrated. Statistical comparisons among the $\mathrm{RR}_{4,5} \mathrm{MCV}, \mathrm{RR}_{3,4} \mathrm{MCV}, \mathrm{RR}_{2,3} \mathrm{MCV}$ and $\mathrm{SH} \mathrm{MCV}$ charts are enumerated in Section 3. Lastly, the research findings and suggestions for future research are given in the last section.

\section{Two One-sided 4-out-of-5 Run Ruks MCV Chars for a Finite Horizon Pocess}

Voinov and Nikulin [30] derived the population MCV statistic as $\gamma=\left(\boldsymbol{\mu}^{T} \boldsymbol{\Sigma}^{-1} \boldsymbol{\mu}\right)^{-\frac{1}{2}}$, where $\boldsymbol{\mu}$ and $\boldsymbol{\Sigma}$ refer to the mean vector and covariance matrix, respectively. Note that $\gamma$ can be estimated by the sample MCV, $\hat{\gamma}$ when $\boldsymbol{\mu}$ and $\boldsymbol{\Sigma}$ are unspecified. Thus, $\hat{\gamma}=\left(\overline{\boldsymbol{X}}^{T} \boldsymbol{S}^{-1} \overline{\boldsymbol{X}}\right)^{-\frac{1}{2}}$ by replacing $\boldsymbol{\mu}$ and $\Sigma$ with $\overline{\boldsymbol{X}}$ and $\boldsymbol{S}$, respectively. Here, $\overline{\boldsymbol{X}}$ is the sample mean vector whereas $\boldsymbol{S}$ is the sample covariance matrix. The computations of $\overline{\boldsymbol{X}}$ and $\boldsymbol{S}$ are:

$$
\overline{\boldsymbol{X}}=\frac{1}{n} \sum_{t=1}^{n} \boldsymbol{X}_{t}
$$

and

$$
\boldsymbol{S}=\frac{1}{n-1} \sum_{t=1}^{n}\left(\boldsymbol{X}_{t}-\overline{\boldsymbol{X}}\right)\left(\boldsymbol{X}_{t}-\overline{\boldsymbol{X}}\right)^{T}
$$

respectively, where $\overline{\boldsymbol{X}}$ and $\boldsymbol{S}$ are independent of one another.

The run rules scheme monitors a process by looking at the number of samples that fall outside the warning limits, out of a certain number of successive samples. For example, $m$-outof- $k$ run rules will generate an out-of-control signal if $m$ out of $k$ consecutive samples fall outside the warning limits. Incorporating a run rules scheme is known to improve the performance of the control chart. In the two one-sided $\mathrm{RR}_{4,5} \mathrm{MCV}$ charts, an out-of-control signal is triggered when four out of five successive multivariate samples are plotted above the upper warning limit (UWL) or lower warning limit (LWL) of the one-sided chart. The RR chart only consists of a warning limit instead of a control limit. In this case, the incontrol region of the chart is tightened so that the chart can give an out-of-control signal quicker by incorporating the run rules scheme. The UWL and LWL of the $\mathrm{RR}_{4,5} \mathrm{MCV}$ charts can be computed as:

$$
\mathrm{UWL}=F_{\hat{\gamma}}^{-1}\left(1-K \mid n, p, \delta_{0}\right),
$$

and

$$
\mathrm{LWL}=F_{\hat{\gamma}}^{-1}\left(K \mid n, p, \delta_{0}\right),
$$

respectively, where $\delta_{0}=n / \gamma_{0}^{2}$ and the $K$ value is determined such that the in-control TARL, i.e. $\mathrm{TARL}_{0}=I$ when the process $\mathrm{MCV}$ is in-control. $p$ denotes the number of quality characteristics.

Equations (3) and (4) follow an inverse cumulative distribution function (cdf) of $\hat{\gamma}$, i.e. $F_{\hat{\gamma}}^{-1}(\alpha \mid n, p, \delta)=$ $\sqrt{[(n(n-p)) /((n-1) p)] \times\left(1 / F_{F}^{-1}(1-\alpha \mid p, n-p, \delta)\right)}$. Here, $F_{F}^{-1}(\cdot)$ refers to an inverse cdf of a noncentral $F$ distribution, where this distribution is only valid when $p<n$ due to the degree of freedom. Here, $\delta$ is defined as $n /\left(\tau \gamma_{0}\right)^{2}$, where the shift size $\tau=1$ when the process is incontrol. Note that $\gamma_{1}=\tau \gamma_{0}$ is the out-of-control MCV, where $\tau \neq 1$, with the values of $\tau>1$ and $0<\tau<1$ refer to upward and downward MCV shifts, respectively.

Let $S_{U}$ and $S_{L}$ be the probabilities that $\hat{\gamma}$ falls above UWL and below LWL, respectively, then

$$
S_{U}=\operatorname{Pr}\left(\hat{\gamma} \geq \mathrm{UWL} \mid n, p, \delta_{1}\right)=1-F_{\hat{\gamma}}\left(\mathrm{UWL} \mid n, p, \delta_{1}\right),
$$

and

$$
S_{L}=\operatorname{Pr}\left(\hat{\gamma} \leq \mathrm{LWL} \mid n, p, \delta_{1}\right)=F_{\hat{\gamma}}\left(\mathrm{LWL} \mid n, p, \delta_{1}\right) .
$$

Equations (5) and (6) follow the cdf of $\hat{\gamma}$, i.e. $F_{\hat{\gamma}}(x \mid n, p, \delta)$ $=1-F_{F}\left[(n(n-p)) /\left((n-1) p x^{2}\right) \mid p, n-p, \delta\right]$, where $F_{F}(\cdot)$ denotes the cdf of a non-central $F$ distribution, and $\delta_{1}=n / \gamma_{1}^{2}$.

Subsequently, a Markov chain approach is applied to derive the formulae for the TARL of the proposed $\mathrm{RR}_{4,5} \mathrm{MCV}$ charts in a finite horizon process. The TARL value of the proposed charts can be computed as 


$$
\mathrm{TARL}=\mathbf{q}\left(\sum_{i=0}^{I} \mathbf{Q}\right) \mathbf{1},
$$

where $\mathbf{Q}$ is the transition probability matrix (tpm) for the transient states and $\mathbf{1}=(1,1,1, \ldots, 1,1)^{\mathrm{T}}$. Here, $\mathbf{q}=(0,0,0, \ldots$, $0,1)^{\mathrm{T}}$ for the proposed $\mathrm{RR}_{4,5} \mathrm{MCV}$ charts. The $\mathrm{RR}_{4,5} \mathrm{MCV}$ charts consist of fifteen transient states, depending on the position of the last five samples plotted on the chart.

\subsection{Upward $\mathrm{RR}_{4,5} \mathrm{MCV}$ Chart}

The transient states of the upward $\mathrm{RR}_{4,5} \mathrm{MCV}$ chart are defined as follows:

State 1: 1st, 2nd and 3rd samples above UWL and 4th sample below UWL;

State 2: 1st and 2nd samples above UWL, 3rd sample below UWL and 4th sample above UWL;

State 3: 1st and 2nd samples above UWL and 3rd and 4th samples below UWL;

State 4: 1st sample above UWL, 2nd sample below UWL, 3rd and 4th samples above UWL;

State 5: 1st sample above UWL, 2nd sample below UWL, 3rd sample above UWL and 4th sample below UWL;

State 6: 1st sample above UWL, 2nd and 3rd samples UWL and 4th sample above UWL;

State 7: 1st sample above UWL and 2nd, 3rd and 4th samples below UWL;

State 8: 1st sample below UWL and 2nd, 3rd and 4th samples above UWL;

State 9: 1st sample below UWL, 2nd and 3rd samples above UWL and 4th sample below UWL;

State 10: 1st sample below UWL, 2nd sample above UWL, 3rd sample below UWL and 4th sample above UWL;

State 11: 1st sample below UWL, 2nd sample above UWL, 3 rd and 4th samples below UWL;

State 12: 1st and 2nd samples below UWL and 3rd and 4th samples above UWL;

State 13: 1st and 2nd samples below UWL, 3rd sample above UWL and 4th sample below UWL;

State 14: 1st, 2nd and 3rd samples below UWL and 4th sample above UWL;

State 15: four successive samples below UWL.

The tpm $\mathbf{Q}$ of the upward $\mathrm{RR}_{4,5} \mathrm{MCV}$ chart is:

$\mathbf{Q}=\left(\begin{array}{ccccccccccccccc}0 & 0 & 1-S_{U} & 0 & 0 & 0 & 0 & 0 & 0 & 0 & 0 & 0 & 0 & 0 & 0 \\ 0 & 0 & 0 & 0 & 1-S_{U} & 0 & 0 & 0 & 0 & 0 & 0 & 0 & 0 & 0 & 0 \\ 0 & 0 & 0 & 0 & 0 & S_{U} & 1-S_{U} & 0 & 0 & 0 & 0 & 0 & 0 & 0 & 0 \\ 0 & 0 & 0 & 0 & 0 & 0 & 0 & 0 & 1-S_{U} & 0 & 0 & 0 & 0 & 0 & 0 \\ 0 & 0 & 0 & 0 & 0 & 0 & 0 & 0 & 0 & S_{U} & 1-S_{U} & 0 & 0 & 0 & 0 \\ 0 & 0 & 0 & 0 & 0 & 0 & 0 & 0 & 0 & 0 & 0 & S_{U} & 1-S_{U} & 0 & 0 \\ 0 & 0 & 0 & 0 & 0 & 0 & 0 & 0 & 0 & 0 & 0 & 0 & 0 & S_{U} & 1-S_{U} \\ 1-S_{U} & 0 & 0 & 0 & 0 & 0 & 0 & 0 & 0 & 0 & 0 & 0 & 0 & 0 & 0 \\ 0 & S_{U} & 1-S_{U} & 0 & 0 & 0 & 0 & 0 & 0 & 0 & 0 & 0 & 0 & 0 & 0 \\ 0 & 0 & 0 & S_{U} & 1-S_{U} & 0 & 0 & 0 & 0 & 0 & 0 & 0 & 0 & 0 & 0 \\ 0 & 0 & 0 & 0 & 0 & S_{U} & 1-S_{U} & 0 & 0 & 0 & 0 & 0 & 0 & 0 & 0 \\ 0 & 0 & 0 & 0 & 0 & 0 & 0 & S_{U} & 1-S_{U} & 0 & 0 & 0 & 0 & 0 & 0 \\ 0 & 0 & 0 & 0 & 0 & 0 & 0 & 0 & 0 & S_{U} & 1-S_{U} & 0 & 0 & 0 & 0 \\ 0 & 0 & 0 & 0 & 0 & 0 & 0 & 0 & 0 & 0 & 0 & S_{U} & 1-S_{U} & 0 & 0 \\ 0 & 0 & 0 & 0 & 0 & 0 & 0 & 0 & 0 & 0 & 0 & 0 & 0 & S_{U} & 1-S_{U}\end{array}\right)$

\subsection{Downward $\mathbf{R R}_{4,5} \mathrm{MCV}$ Chart}

The transient states of the downward $\mathrm{RR}_{4,5} \mathrm{MCV}$ chart are defined as follows:

State 1: four successive samples below LWL;
State 2: 1st, 2nd and 3rd samples above LWL and 4th sample below LWL;

State 3: 1st and 2nd samples above LWL, 3rd sample below LWL and 4th sample above LWL;

State 4: 1st and 2nd samples above LWL and 3rd and 4th samples below LWL;

State 5: 1st sample above LWL, 2nd sample below LWL, 3rd and 4th samples above LWL;

State 6: 1st sample above LWL, 2nd sample below LWL, 3rd sample above LWL and 4th sample below LWL;

State 7: 1st sample above LWL, 2nd and 3rd samples below LWL and 4th sample above LWL;

State 8: 1st sample above LWL and 2nd, 3rd and 4th samples below LWL;

State 9: 1st sample below LWL and 2nd, 3rd and 4th samples above LWL;

State 10: 1st sample below LWL, 2nd and 3rd samples above LWL and 4th sample below LWL;

State 11: 1st sample below LWL, 2nd sample above LWL, 3rd sample below LWL and 4th sample above LWL;

State 12: 1st sample below LWL, 2nd sample above LWL, 3rd and 4th samples below LWL;

State 13: 1st and 2nd samples below LWL and 3rd and 4th samples above LWL;

State 14: 1st and 2nd samples below LWL, 3rd sample above LWL and 4th sample below LWL;

State 15: 1st, 2nd and 3rd samples below LWL and 4th sample above LWL.

The tpm $\mathbf{Q}$ of the downward $\mathrm{RR}_{4,5} \mathrm{MCV}$ chart can be obtained as

$\mathbf{Q}=\left(\begin{array}{ccccccccccccccc}1-S_{L} & S_{L} & 0 & 0 & 0 & 0 & 0 & 0 & 0 & 0 & 0 & 0 & 0 & 0 & 0 \\ 0 & 0 & 1-S_{L} & S_{L} & 0 & 0 & 0 & 0 & 0 & 0 & 0 & 0 & 0 & 0 & 0 \\ 0 & 0 & 0 & 0 & 1-S_{L} & S_{L} & 0 & 0 & 0 & 0 & 0 & 0 & 0 & 0 & 0 \\ 0 & 0 & 0 & 0 & 0 & 0 & 1-S_{L} & S_{L} & 0 & 0 & 0 & 0 & 0 & 0 & 0 \\ 0 & 0 & 0 & 0 & 0 & 0 & 0 & 0 & 1-S_{L} & S_{L} & 0 & 0 & 0 & 0 & 0 \\ 0 & 0 & 0 & 0 & 0 & 0 & 0 & 0 & 0 & 0 & 1-S_{L} & S_{L} & 0 & 0 & 0 \\ 0 & 0 & 0 & 0 & 0 & 0 & 0 & 0 & 0 & 0 & 0 & 0 & 1-S_{L} & S_{L} & 0 \\ 0 & 0 & 0 & 0 & 0 & 0 & 0 & 0 & 0 & 0 & 0 & 0 & 0 & 0 & 1-S_{L} \\ 1-S_{L} & S_{L} & 0 & 0 & 0 & 0 & 0 & 0 & 0 & 0 & 0 & 0 & 0 & 0 & 0 \\ 0 & 0 & 1-S_{L} & S_{L} & 0 & 0 & 0 & 0 & 0 & 0 & 0 & 0 & 0 & 0 & 0 \\ 0 & 0 & 0 & 0 & 1-S_{L} & S_{L} & 0 & 0 & 0 & 0 & 0 & 0 & 0 & 0 & 0 \\ 0 & 0 & 0 & 0 & 0 & 0 & 1-S_{L} & 0 & 0 & 0 & 0 & 0 & 0 & 0 & 0 \\ 0 & 0 & 0 & 0 & 0 & 0 & 0 & 0 & 1-S_{L} & S_{L} & 0 & 0 & 0 & 0 & 0 \\ 0 & 0 & 0 & 0 & 0 & 0 & 0 & 0 & 0 & 0 & 1-S_{L} & 0 & 0 & 0 & 0 \\ 0 & 0 & 0 & 0 & 0 & 0 & 0 & 0 & 0 & 0 & 0 & 0 & 1-S_{L} & 0 & 0\end{array}\right)$

\section{Statistical Comparison}

In this section, the statistical performance of the proposed charts is evaluated in terms of the TARL criterion. Tables $1-$ 3 present the comparison between the $\mathrm{RR}_{4,5} \mathrm{MCV}, \mathrm{RR}_{2,3} \mathrm{MCV}$ [23], $\mathrm{RR}_{3,4} \mathrm{MCV}$ [23] and SH MCV [22] charts, in terms of the TARL 1 values, for $p=2, \gamma_{0} \in\{0.1,0.3\}, n \in\{5,10\}$, $I \in\{30,50\}$ and $\tau \in\{0.50,0.60,0.75,0.90,1.15,1.25,1.50$, $2.00\}$. In the detection of upward MCV shifts, it is obvious that $\mathrm{RR}_{2,3} \mathrm{MCV}$ chart has the best performance, for small and moderate downward shift sizes, when the sample size $n$ is small and the production horizon $I$ is short. For example, from Table 1, when $p=2, I=30, n=5, \gamma_{0}=0.1$ and $\tau=1.25$, the $\mathrm{RR}_{4,5} \mathrm{MCV}, \mathrm{RR}_{2,3} \mathrm{MCV}, \mathrm{RR}_{3,4} \mathrm{MCV}$ and $\mathrm{SH} \mathrm{MCV}$ charts provide $\mathrm{TARL}_{1}=21.80,21.10,21.34$ and 21.82, respectively, where the $\mathrm{RR}_{2,3} \mathrm{MCV}$ chart has the smallest $\mathrm{TARL}_{1}$ value. However, when the sample size and the production horizon increase, the $\mathrm{RR}_{4,5} \mathrm{MCV}$ chart prevails over other $\mathrm{MCV}$ charts. In the detection of downward MCV shifts, the $\mathrm{RR}_{4,5} \mathrm{MCV}$ chart provides the best performance among the 
MCV charts. For example, from Table 2, when $p=2, I=50$, $n=10, \gamma_{0}=0.1$ and $\tau=0.75$, the $\mathrm{RR}_{4,5} \mathrm{MCV}, \mathrm{RR}_{2,3} \mathrm{MCV}$, $\mathrm{RR}_{3,4} \mathrm{MCV}$ and $\mathrm{SH} \mathrm{MCV}$ charts give $\mathrm{TARL}_{1}=19.28,33.15$, 24.25 and 41.22 , respectively, where the $R_{4,5} \mathrm{MCV}$ chart has the smallest $\mathrm{TARL}_{1}$ value.

Table 1. TARL $L_{1}$ values of the $\mathrm{RR}_{4,5} \mathrm{MCV}, \mathrm{RR}_{2,3} \mathrm{MCV}$, $\mathrm{RR}_{3,4} \mathrm{MCV}$ and SH MCV charts when $p=2$ and $I=30$

\begin{tabular}{|c|c|c|c|c|}
\hline & $\mathrm{RR}_{4,5} \mathrm{MCV}$ & $\mathrm{RR}_{2,3} \mathrm{MCV}$ & $\mathrm{RR}_{3,4} \mathrm{MCV}$ & SH MCV \\
\hline & \multicolumn{4}{|c|}{$\gamma_{0}=0.1$} \\
\hline$\tau$ & \multicolumn{4}{|c|}{$n=5$} \\
\hline 0.50 & 7.03 & 13.91 & 8.60 & 24.30 \\
\hline 0.60 & 12.40 & 20.77 & 15.46 & 26.80 \\
\hline 0.75 & 23.09 & 26.83 & 24.82 & 28.95 \\
\hline 0.90 & 28.64 & 29.27 & 28.93 & 29.64 \\
\hline 1.15 & 26.02 & 25.82 & 25.86 & 26.22 \\
\hline 1.25 & 21.80 & 21.10 & 21.34 & 21.82 \\
\hline 1.50 & 12.44 & 10.50 & 11.39 & 10.67 \\
\hline \multirow[t]{2}{*}{2.00} & 6.29 & 4.23 & 5.25 & 3.40 \\
\hline & \multicolumn{4}{|c|}{$n=10$} \\
\hline 0.50 & 4.11 & 2.92 & 3.29 & 6.04 \\
\hline 0.60 & 4.61 & 5.65 & 4.66 & 13.88 \\
\hline 0.75 & 11.93 & 17.95 & 13.85 & 22.51 \\
\hline 0.90 & 26.38 & 27.93 & 27.06 & 28.95 \\
\hline 1.15 & 21.62 & 21.97 & 21.59 & 23.50 \\
\hline 1.25 & 14.04 & 13.78 & 13.65 & 15.89 \\
\hline 1.50 & 6.25 & 4.73 & 5.43 & 4.71 \\
\hline \multirow[t]{2}{*}{2.00} & 4.29 & 2.42 & 3.34 & 1.59 \\
\hline & \multicolumn{4}{|c|}{$\gamma_{0}=0.3$} \\
\hline$\tau$ & \multicolumn{4}{|c|}{$n=5$} \\
\hline 0.50 & 7.35 & 14.45 & 9.06 & 24.58 \\
\hline 0.60 & 13.02 & 21.20 & 16.09 & 26.97 \\
\hline 0.75 & 23.50 & 26.99 & 25.12 & 28.84 \\
\hline 0.90 & 28.71 & 29.31 & 28.98 & 29.66 \\
\hline 1.15 & 26.34 & 26.18 & 26.20 & 26.57 \\
\hline 1.25 & 22.51 & 21.93 & 22.19 & 22.67 \\
\hline 1.50 & 13.62 & 11.85 & 12.64 & 12.30 \\
\hline \multirow[t]{2}{*}{2.00} & 7.00 & 4.93 & 5.95 & 4.25 \\
\hline & \multicolumn{4}{|c|}{$n=10$} \\
\hline 0.50 & 4.14 & 3.08 & 3.36 & 6.72 \\
\hline 0.60 & 5.10 & 6.14 & 4.95 & 14.90 \\
\hline 0.75 & 12.84 & 18.76 & 14.82 & 23.69 \\
\hline 0.90 & 26.68 & 28.06 & 27.28 & 29.02 \\
\hline 1.15 & 22.48 & 22.86 & 22.49 & 24.28 \\
\hline 1.25 & 15.38 & 15.32 & 15.09 & 17.52 \\
\hline 1.50 & 6.96 & 5.57 & 6.17 & 5.91 \\
\hline 2.00 & 4.49 & 2.68 & 3.57 & 1.95 \\
\hline
\end{tabular}

Table 2. TARL $L_{1}$ values of the $\mathrm{RR}_{4,5} \mathrm{MCV}, \mathrm{RR}_{2,3} \mathrm{MCV}$, $\mathrm{RR}_{3,4} \mathrm{MCV}$ and SH MCV charts when $p=2$ and $I=50$

\begin{tabular}{|c|c|c|c|c|}
\hline & $\mathrm{RR}_{4,5} \mathrm{MCV}$ & $\mathrm{RR}_{2,3} \mathrm{MCV}$ & $\mathrm{RR}_{3,4} \mathrm{MCV}$ & $\mathrm{SH} \mathrm{MCV}$ \\
\hline & \multicolumn{4}{|c|}{$\gamma_{0}=0.1$} \\
\hline$\tau$ & \multicolumn{4}{|c|}{$n=5$} \\
\hline 0.50 & 10.26 & 27.41 & 14.85 & 43.80 \\
\hline 0.60 & 21.39 & 38.52 & 28.57 & 46.62 \\
\hline 0.75 & 40.71 & 46.48 & 43.62 & 49.25 \\
\hline 0.90 & 48.43 & 49.24 & 48.82 & 49.63 \\
\hline 1.15 & 43.88 & 43.90 & 43.77 & 44.71 \\
\hline
\end{tabular}

\begin{tabular}{|c|c|c|c|c|}
\hline 1.25 & 35.88 & 35.50 & 35.45 & 37.32 \\
\hline 1.50 & 17.20 & 15.13 & 15.96 & 16.50 \\
\hline 2.00 & 7.09 & 4.95 & 5.99 & 4.26 \\
\hline & \multicolumn{4}{|c|}{$n=10$} \\
\hline 0.50 & 4.24 & 3.83 & 3.60 & 12.42 \\
\hline 0.60 & 5.71 & 9.21 & 6.08 & 27.96 \\
\hline 0.75 & 19.28 & 33.15 & 24.25 & 41.22 \\
\hline 0.90 & 45.31 & 47.65 & 46.39 & 48.87 \\
\hline 1.15 & 36.00 & 37.55 & 36.39 & 40.58 \\
\hline 1.25 & 20.85 & 21.99 & 20.87 & 27.05 \\
\hline 1.50 & 7.21 & 5.88 & 6.42 & 6.57 \\
\hline \multirow[t]{2}{*}{2.00} & 4.40 & 2.56 & 3.46 & 1.80 \\
\hline & \multicolumn{4}{|c|}{$\gamma_{0}=0.3$} \\
\hline$\tau$ & \multicolumn{4}{|c|}{$n=5$} \\
\hline 0.50 & 10.90 & 28.22 & 15.81 & 44.12 \\
\hline 0.60 & 22.62 & 39.05 & 29.68 & 46.80 \\
\hline 0.75 & 41.34 & 46.63 & 44.02 & 48.76 \\
\hline 0.90 & 48.54 & 49.26 & 48.87 & 49.65 \\
\hline 1.15 & 44.44 & 44.50 & 44.36 & 45.26 \\
\hline 1.25 & 37.30 & 37.08 & 36.95 & 38.84 \\
\hline 1.50 & 19.45 & 17.65 & 18.30 & 19.60 \\
\hline 2.00 & 8.12 & 5.97 & 7.00 & 5.57 \\
\hline & \multicolumn{4}{|c|}{$n=10$} \\
\hline 0.50 & 4.31 & 4.10 & 3.73 & 13.94 \\
\hline 0.60 & 6.05 & 10.11 & 6.60 & 29.70 \\
\hline 0.75 & 21.08 & 34.35 & 26.05 & 42.23 \\
\hline 0.90 & 45.73 & 47.80 & 46.68 & 48.95 \\
\hline 1.15 & 37.68 & 39.15 & 38.07 & 41.84 \\
\hline 1.25 & 23.55 & 25.01 & 23.70 & 30.12 \\
\hline 1.50 & 8.29 & 7.19 & 7.56 & 8.61 \\
\hline 2.00 & 4.67 & 2.92 & 3.77 & 2.31 \\
\hline
\end{tabular}

Table 3. Summary of the performance comparisons

\begin{tabular}{|c|c|c|}
\hline & \multicolumn{2}{|c|}{$I=30$} \\
\hline & $\gamma_{0}=0.1$ & $\gamma_{0}=0.3$ \\
\hline$\tau$ & \multicolumn{2}{|c|}{$n=5$} \\
\hline 0.50 & $\mathbf{R R}_{4,5} \mathbf{M C V}$ & $\mathrm{RR}_{4,5} \mathrm{MCV}$ \\
\hline 0.60 & $\mathrm{RR}_{4,5} \mathrm{MCV}$ & $\mathrm{RR}_{4,5} \mathrm{MCV}$ \\
\hline 0.75 & RR4,5MCV & $\mathrm{RR}_{4,5} \mathrm{MCV}$ \\
\hline 0.90 & $\mathrm{RR}_{4,5} \mathrm{MCV}$ & $\mathrm{RR}_{4,5} \mathrm{MCV}$ \\
\hline 1.15 & $\mathrm{RR}_{2,3} \mathrm{MCV}$ & $\mathrm{RR}_{2,3} \mathrm{MCV}$ \\
\hline 1.25 & $\mathrm{RR}_{2,3} \mathrm{MCV}$ & $\mathrm{RR}_{2,3} \mathrm{MCV}$ \\
\hline 1.50 & $\mathrm{RR}_{2,3} \mathrm{MCV}$ & $\mathrm{RR}_{2,3} \mathrm{MCV}$ \\
\hline \multirow[t]{2}{*}{2.00} & $\mathrm{RR}_{2,3} \mathrm{MCV}$ & SH MCV \\
\hline & \multicolumn{2}{|c|}{$n=10$} \\
\hline 0.50 & $\mathrm{RR}_{2,3} \mathrm{MCV}$ & $\mathrm{RR}_{2,3} \mathrm{MCV}$ \\
\hline 0.60 & $\mathbf{R R}_{4,5} \mathbf{M C V}$ & $\mathbf{R R}_{4,5} \mathbf{M C V}$ \\
\hline 0.75 & $\mathrm{RR}_{4,5} \mathrm{MCV}$ & $\mathrm{RR}_{4,5} \mathrm{MCV}$ \\
\hline 0.90 & $\mathbf{R R}_{4,5} \mathbf{M C V}$ & $\mathbf{R R}_{4,5} \mathrm{MCV}$ \\
\hline 1.15 & $\mathrm{RR}_{3,4} \mathrm{MCV}$ & $\mathrm{RR}_{4,5} \mathrm{MCV}$ \\
\hline 1.25 & $\mathrm{RR}_{3,4} \mathrm{MCV}$ & $\mathrm{RR}_{3,4} \mathrm{MCV}$ \\
\hline 1.50 & SH MCV & $\mathrm{RR}_{2,3} \mathrm{MCV}$ \\
\hline \multirow[t]{3}{*}{2.00} & SH MCV & SH MCV \\
\hline & \multicolumn{2}{|c|}{$I=50$} \\
\hline & $\gamma_{0}=0.1$ & $\gamma_{0}=0.3$ \\
\hline$\tau$ & \multicolumn{2}{|c|}{$n=5$} \\
\hline 0.50 & $\mathbf{R R}_{4,5} \mathbf{M C V}$ & $\mathrm{RR}_{4,5} \mathrm{MCV}$ \\
\hline 0.60 & $\mathrm{RR}_{4,5} \mathrm{MCV}$ & $\mathrm{RR}_{4,5} \mathrm{MCV}$ \\
\hline 0.75 & $\mathrm{RR}_{4,5 \mathrm{MCV}}$ & $\mathrm{RR}_{4,5} \mathrm{MCV}$ \\
\hline
\end{tabular}




\begin{tabular}{|l|l|l|}
\hline 0.90 & $\mathbf{R R}_{\mathbf{4}, \mathbf{5}} \mathbf{M C V}$ & $\mathbf{R R}_{\mathbf{4}, \mathbf{5}} \mathbf{M C V}$ \\
\hline 1.15 & $\mathrm{RR}_{3,4} \mathrm{MCV}$ & $\mathrm{RR}_{3,4} \mathrm{MCV}$ \\
\hline 1.25 & $\mathrm{RR}_{3,4} \mathrm{MCV}$ & $\mathrm{RR}_{3,4} \mathrm{MCV}$ \\
\hline 1.50 & $\mathrm{RR}_{2,3} \mathrm{MCV}$ & $\mathrm{RR}_{2,3} \mathrm{MCV}$ \\
\hline 2.00 & $\mathrm{SH} \mathrm{MCV}$ & $\mathrm{SH} \mathrm{MCV}$ \\
\hline \multicolumn{2}{|c|}{$n=10$} \\
\hline 0.50 & $\mathrm{RR}_{3,4} \mathrm{MCV}$ & $\mathrm{RR}_{3,4} \mathrm{MCV}$ \\
\hline 0.60 & $\mathbf{R R}_{\mathbf{4}, \mathbf{5}} \mathbf{M C V}$ & $\mathbf{R R}_{\mathbf{4}, \mathbf{5}} \mathbf{M C V}$ \\
\hline 0.75 & $\mathbf{R R}_{\mathbf{4}, \mathbf{5}} \mathbf{M C V}$ & $\mathbf{R R}_{\mathbf{4}, \mathbf{5}} \mathbf{M C V}$ \\
\hline 0.90 & $\mathbf{R R}_{\mathbf{4}, \mathbf{5}} \mathbf{M C V}$ & $\mathbf{R R}_{\mathbf{4}, \mathbf{5}} \mathbf{M C V}$ \\
\hline 1.15 & $\mathbf{R R}_{\mathbf{4}, \mathbf{5}} \mathbf{M C V}$ & $\mathbf{R R}_{\mathbf{4}, \mathbf{5}} \mathbf{M C V}$ \\
\hline 1.25 & $\mathbf{R R}_{\mathbf{4}, \mathbf{5}} \mathbf{M C V}$ & $\mathbf{R R}_{\mathbf{4}, \mathbf{5}} \mathbf{M C V}$ \\
\hline 1.50 & $\mathrm{RR}_{2,3} \mathrm{MCV}$ & $\mathrm{RR}_{2,3} \mathrm{MCV}$ \\
\hline 2.00 & $\mathrm{SH}_{\mathrm{MCV}}$ & $\mathrm{SH}_{\mathrm{MCV}}$ \\
\hline
\end{tabular}

\section{Conclusion}

In this paper, two one-sided $\mathrm{RR}_{4,5} \mathrm{MCV}$ charts are proposed for enhancing a multivariate finite horizon process monitoring. The performances of these charts are measured in terms of the TARL criterion based on the Markov-chain approach. The numerical comparisons reveal that the $\mathrm{RR}_{4,5} \mathrm{MCV}$ charts outperform the $\mathrm{RR}_{2,3} \mathrm{MCV}, \mathrm{RR}_{3,4} \mathrm{MCV}$ and $\mathrm{SH}$ MCV charts, for detecting small or moderate shifts in a finite horizon process, especially in detecting the downward process shifts. No attempt has been made to improve the efficiency of the multivariate process monitoring in a finite horizon process based on the 4-out-of-5 run rules scheme in the existing literature. The motivation of this research is to develop control charts that are simple to implement in industries. It should be highlighted that the proposed scheme can be viewed as an important framework for quality engineers who wish to use an intermediate control chart instead of a more advanced control chart, with the consideration of cost and time efficiencies. It cannot be denied that the proposed intermediate scheme is useful for certain finite horizon process monitoring. In the future, this research can be extended to the $\mathrm{RR}_{4,5} \mathrm{MCV}$ charts with the presence of measurement errors and estimated parameters for monitoring the finite horizon process.

\section{Acknowledgement}

This work was funded by the Ministry of Higher Education Malaysia, Fundamental Research Grant Scheme [Grant Number 203.PMGT.6711755]

\section{References}

[1] J.J.J. Babu, G.F. Sudha, Adaptive speckle reduction in ultrasound images using fuzzy logic on coefficient of variation, Biomedical Signal Processing and Control, Vol. 23, pp. 93-103, 2016.

[2] S.A. Karthik, S.S. Manjunath, Automatic gridding of noisy microarray images based on coefficient of variation, Informatics in Medicine Unlocked, Vol. 17, 100264, 2019.

[3] M. Amelio, Olive oil sensory evaluation: An alternative to the robust coefficient of variation $(\mathrm{CVr} \%)$ for measuring panel group performance in official tasting sessions, Trends in Food Science \& Technology, Vol. 88, pp. 567-570, 2019.

[4] A. Bakowski, L. Radziszewski, M. Zmindak, Analysis of the coefficient of variation for injection pressure in a compression ignition engine, Procedia Engineering, Vol. 177, pp. 297-302, 2017.

[5] R. Calif, T. Soubdhan, On the use of the coefficient of variation to measure spatial and temporal correlation of global solar radiation, Renewable Energy, Vol. 88, pp. 192-199, 2016.

[6] C.W. Kang, M.S. Lee, Y.J. Seong, D.M. Hawkins, A control chart for the coefficient of variation, Journal of Quality Technology, Vol. 39, pp. 151-158, 2007.

[7] K.W. Khaw, M.B.C. Khoo, W.C. Yeong, Z. Wu, Monitoring the coefficient of variation using a variable sample size and sampling interval control chart, Communications in Statistics - Simulation and Computation, Vol. 46, pp. 5772-5794, 2017.

[8] S.L. Lim, W.C. Yeong, M.B.C. Khoo, Z.L. Chong, K.W. Khaw, An alternative design for the variable sample size coefficient of variation chart based on the median run length and expected median run length, International Journal of Industrial Engineering: Theory, Applications and Practice, Vol. 26, pp. 199220, 2019

[9] K.W. Khaw, X.Y. Chew, A re-evaluation of the run rules control chart for monitoring the coefficient of variation, Statistics, Optimization \& Information Computing, Vol. 7, pp. 716-730, 2019.

[10] R. Chen, Z. Li, J. Zhang, A generally weighted moving average control chart for monitoring the coefficient of variation, Applied Mathematical Modelling, Vol. 70, pp. 190-205, 2019.

[11] W.C. Yeong, M.B.C. Khoo, W.L. Teoh, P. Castagliola, A control chart for the multivariate coefficient of variation, Quality and Reliability Engineering International, Vol. 32, pp. 1213-1225, 2016.

[12] K.W. Khaw, M.B.C. Khoo, P. Castagliola, M.A. Rahim, New adaptive control charts for monitoring the multivariate coefficient of variation, Computers \& Industrial Engineering, Vol. 126, pp. 595-610, 2018.

[13] K.W. Khaw, X.Y. Chew, W.C. Yeong, S.L. Lim, Optimal design of the synthetic control chart for monitoring the multivariate coefficient of variation, Chemometrics and Intelligent Laboratory Systems, Vol. 186, pp. 33-40, 2019

[14] X.Y. Chew, K.W. Khaw, One-sided downward control chart for monitoring the multivariate coefficient of variation with VSSI strategy, Journal of Mathematical and Fundamental Sciences, Vol. 52, pp. 112-130, 2020

[15] X.Y. Chew, M.B.C. Khoo, K.W. Khaw, W.C. Yeong, Z.L. Chong, A proposed variable parameter control chart for monitoring the multivariate coefficient of variation, Quality and Reliability Engineering International, Vol. 35, pp. 2442-2461, 2019.

[16] V. Giner-Bosch, K.P. Tran, P. Castagliola, M.B.C. Khoo, An EWMA control chart for the multivariate coefficient of variation, Quality and Reliability Engineering International, Vol. 35, pp. 1515-1541, 2019.

[17] A. Haq, M.B.C. Khoo, New adaptive EWMA control charts for monitoring univariate and multivariate 
coefficient of variation, Computers \& Industrial Engineering, Vol. 131, pp. 28-40, 2019.

[18] P. Castagliola, A. Amdouni, H. Taleb, G. Celano, Onesided Shewhart-type charts for monitoring the coefficient of variation in short production run, Quality Technology \& Quantitative Management, Vol. 12, pp. 53-67, 2015

[19] S.P. Ladany, Optimal use of control charts for controlling current production, Management Science, Vol. 19, pp. 763-772, 1973.

[20] G. Nenes, G. Tagaras, Evaluation of CUSUM charts for finite-horizon processes, Communications in Statistics - Simulation and Computation, Vol. 39, pp. 578-597, 2010.

[21] G. Celano, P. Castagliola, An EWMA sign control chart with varying control limits for finite horizon processes, Quality and Reliability Engineering International, Vol. 34, pp. 1717-1731, 2018.

[22] M. Khatun, M.B.C. Khoo, M.H. Lee, P. Castagliola, One-sided control charts for monitoring the multivariate coefficient of variation in short production runs, Transactions of the Institute of Measurement and Control, Vol. 41, pp. 1712-1728, 2019.

[23] X.Y. Chew, K.W. Khaw, M.H. Lee, The efficiency of run rules schemes for the multivariate coefficient of variation in short runs process, Communications in Statistics - Simulation and Computation, 2019. DOI: https://doi.org/10.1080/03610918.2019.1704783

[24] K.P. Tran, P. Castagliola, G. Celano, Monitoring the ratio of two normal variables using run rules type control charts, International Journal of Production Research, Vol. 54, pp. 1670-1688, 2016.

[25] A.C. Rakitzis, Monitoring exponential data using twosided control charts with runs rules, Journal of Statistical Computation and Simulation, Vol. 86, pp. 149-159, 2016.

[26] K.P. Tran, Run rules median control charts for monitoring process mean in manufacturing, Quality and Reliability Engineering International, Vol. 33, pp. 2437-2450, 2017.

[27] K.P. Tran, Designing of run rules t control charts for monitoring changes in the process mean. Chemometrics and Intelligent Laboratory Systems, Vol. 174, pp. 85-93, 2018.

[28] S.C. Shongwe, J-C. Malela-Majika, E.M. Rapoo, Onesided and two-sided w-of-w runs-rules schemes: An overall performance perspective and the unified runlength derivations. Journal of Probability and Statistics, Article ID 6187060: 20 pages, 2019.

[29] K.P. Tran, The efficiency of the 4-out-of-5 runs rules scheme for monitoring the ratio of population means of a bivariate normal distribution, International Journal of Reliability, Quality and Safety Engineering, Vol. 23, pp. 1-26, 2016.

[30] V.G. Voinov, M.S. Nikulin, Unbiased estimator and their applications, multivariate case (2nd edn), Kluwer, Dordrecht, 1996.

\section{Creative Commons Attribution License 4.0 (Attribution 4.0 International, CC BY 4.0)}

This article is published under the terms of the Creative Commons Attribution License 4.0 https://creativecommons.org/licenses/by/4.0/deed.en_US 